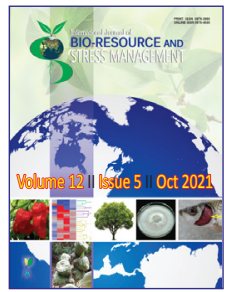

Article AR2234a

DOI: HTTPS://DOI.ORG/10.23910/1.2021.2234a

International Journal of Bio-resource and Stress Management

October 2021

IJBSM 2021, 12(5):490-495

Research Article

Social Science

\title{
Ergonomical Assessment on Hand Operated Chaff Cutter by Rural Women Workers
}

\author{
Sathish Akki, Nirmala Bangi, Suresh Batta, Nagaraj Basani and Balachand Ch.
}

Professor Jayashankar Telangana State Agricultural University, Hyderabad, Telengana (502 001), India

\begin{abstract}
Open Access
Corresponding Author

Sathish Akki

e-mail: sathishakki1537@gmail.com

Citation: Akki et al., 2021. Ergonomical Assessment on Hand Operated Chaff Cutter by Rural Women Workers. International Journal of Bio-resource and Stress Management 2021, 12(5), 490-495. HTTPS:// DOI.ORG/10.23910/1.2021.2234a.

Copyright: (c) 2021 Akki et al. This is an open access article that permits unrestricted use, distribution and reproduction in any medium after the author(s) and source are credited.

Data Availability Statement: Legal restrictions are imposed on the public sharing of raw data. However, authors have full right to transfer or share the data in raw form upon request subject to either meeting the conditions of the original consents and the original research study. Further, access of data needs to meet whether the user complies with the ethical and legal obligations as data controllers to allow for secondary use of the data outside of the original study.
\end{abstract}

Conflict of interests: The authors have declared that no conflict of interest exists.

\begin{abstract}
A study was conducted to ease the fodder cutting operations a commercially available hand chaff cutter (Sokhiya Agricultural Industries, Jaipur, India) during 2019-20 in the Department of Farm Machinery and Power Engineering at College of Agricultural Engineering, Sangareddy, Telangana, India. The assessment was done using with 3 different age group female workers who regularly feed to the animals to assess its suitability for workers of the southern region of India. The parameters used for the Ergonomical evaluation include machine operation at different forces are heart rate, pulse rate, oxygen consumption rate, and energy expenditure rate. The average heart rate for female subjects of P1, P2 and P3 was recorded before the operation is 79, 76 and 81 beats $\mathrm{min}^{-1}$ and after the operation is 109, 108 and 113 beats $\mathrm{min}^{-1}$ for various fodders. The average pulse rate for female subjects of $\mathrm{P} 1, \mathrm{P} 2$, and $\mathrm{P} 3$ was recorded before theoperation is 62,68 , and 63 beats $\mathrm{min}^{-1}$ and after the operation is 80,80 , and 82 beats $\mathrm{min}^{-1}$ for various fodders. The average oxygen consumption rate and energy expenditure rate of female subjects of P1, P2 and P3 were found to be $0.61,0.59$ and 0.66 liter $\mathrm{min}^{-1}$, and $12.68,12.36$ and $13.74 \mathrm{KJ} \mathrm{min}^{-1}$ respectively after operation of chaff cutter. The physiological parameters are heart rate, pulse rate, oxygen consumption rate, and energy consumption rate increased more rapidly for all age group female workers after operation of chaff cutter with 3 various fodders.
\end{abstract}

Keywords: Chaff cutter, ergonomics, EER, fodders, OCR, women workers

\section{Introduction}

The chaff cutter is a simple but indigenous device, used for cutting straw, chaff, hay, and other green/dry fodder into small pieces before being mixed with other forage to feed animals. The chaff cutter provides uniformity of fodder in length. The fodder chopping is done mainly to save storage space, to make the fodder more palatable and to keep the fodder free form spoiling while in storage (Mohan and Kumar, 2004). An un-chopped straw would provide complete choice for the animal to selectively consume more digestible parts and leaving behind the less digestible parts, which consequently leads to substantial feed wastage (Jalali et al., 2012). Also, the animal might need to spend more energy to chew the unchopped straw, than the chopped straw. Chaffing fodders and straws to small pieces and then feeding to animals improves the digestibility (Chander, 2010).

Agriculture ranks one of the hazardous industries as it has potentially much harmful health impact causing immense pain and hardships (verma et al., 2020). Use of traditional tools for long hours with inappropriate working

\section{Article History}

RECEIVED on $30^{\text {th }}$ March 2021 RECEIVED in revised form on 29 $9^{\text {th }}$ September 2021 ACCEPTED in final form on $20^{\text {th }}$ October 2021 
posture in field leads to drudgery (Singh, 2014). The discomfort in the body parts was primarily caused by the leaning pose adopted when beating paddy crop bundles on the drum, whereas discomfort in the lower leg was caused by pedalling and feeding the crop in a bent posture by using a manually operated paddy thresher (Kathrivel and Sivakumar, 2003). Therefore, attention needs to be given to their capabilities and limitations during design and operation of various farm equipment's, to get higher productivity, enhanced comfort and ensure better safety (Yadav et al., 2010). Ergonomics is the scientific study of the relationship between man and his working environment. The goal of ergonomics is to design a workplace to confirm to the physiological, psychological, and behavioural capabilities of workers. Its objective is to increase the efficiency of human activity by removing those features of the design that are likely to cause inefficiency or physical disability in the long term and thus to minimize the cost of operation. The application of ergonomics had the potential to relieve at least some of the drudgery associated with agricultural tasks carried out by tropical farmers (Bridger et al., 2018). Ergonomical study of hand chaff cutter was felt very important to increase the man-machine system efficiently and to improve the operator's health. Michael and ojha (1980) stated that manpower is the main source for operating small tools and equipment's. There are more than 200 million agricultural workers of which more than $35 \%$ are female workers and are engaged in all types of agricultural tasks (Mohanty et al., 2012). Socioeconomic factors such as age, family income, and land ownership had a significant impact on farm women's participation in agriculture (Chayal and Dhaka, 2010).

Singh and Gite., 2007 evaluated the winnower to measure the mean heart rate of the women workers and their output. During the operation, the average heart rate of female staff was found to be 112 beats $\mathrm{min}^{-1}$. Since the heart rate is within reasonable limits, the equipment produced was considered to be ideal for use by women employees. The body dimensions of workers and the environmental factors like temperature and humidity have reflected their influence on performance of workers (Jha and Tiwari, 2014).

Given the above, it was planned to investigate on handoperated chaff cutter for Ergonomical studies with the objectives are 1). To study the physiological response of different age group female workers in operation of chaff cutter, and 2). To evaluate the energy requirement and oxygen consumption rate for cutting three different fodders.

\section{Materials and Methods}

\subsection{Experimental site and climatic condition}

The experiment was conducted during 2019-20 in the Department of Farm Machinery and Power Engineering at College of Agricultural Engineering, Sangareddy, Telangana, India. It is situated in the northern region of the Indian state of Telangana at $17.586^{\circ} \mathrm{N}$ latitude $78.126802^{\circ} \mathrm{E}$ longitude at an altitude of $496 \mathrm{~m}(1.627 \mathrm{ft})$ above the mean sea level. The average temperature is $26.6^{\circ} \mathrm{C}$ and the average rainfall is $930 \mathrm{~mm}$.

The present study deals with the evaluation of the hand operated chaff cutter for Ergonomical consideration. During physical activities, there is an increase in physiological parameters depending upon the workload on the individual agricultural workers, especially in female workers. Further parameters like heart rat pulse rate, oxygen consumption rate, will not allow the worker to perform the given task more effectively. Filed experiments were carried out to assess the physiological workload of selected female operators in terms of heart rate, pulse rate response during chaff cutting operation of different fodders.

\subsection{Selection of subjects and samples}

So three female subjects in the age group of 20-50 years were selected. They were medically fit and regular chaff cutter operators. The experiments were conducted on three different wet fodders of jowar, pearl millet and elephant grass which are regular feed to the animals. Anthropometric body dimensions play a significant role in human-machine interaction. The overall working efficiency of human-machine environment and resultant discomfort has severe impact while using farm tools and machinery in hills (Agrawal et al., 2010). The physical parameters of selected subjects for performance evaluation of manually operated chaff cutter were shown in Table 1.

\begin{tabular}{lcccc}
\hline \multicolumn{4}{l}{ Table 1: Categorization of agricultural work (Nag et al., 1980) } \\
\hline Variables & Light & Moderate & Heavy & $\begin{array}{c}\text { Extremely } \\
\text { heavy }\end{array}$ \\
\hline VO2 Max (\%) & $<25 \%$ & Up to 50\% & Up to & Above \\
& & & $75 \%$ & $75 \%$ \\
O2 & $0-0.435$ & $0.436-$ & $0.871-$ & $>1.306$ \\
Consumption, & & 0.870 & 1.305 & \\
(L min m $^{-1}$ ) & & & & \\
EER (KJ min & & & \\
& $<9.10$ & $9.11-$ & $18.16-$ & $>27.23$ \\
& & 18.15 & 27.22 & \\
\hline
\end{tabular}

\subsection{Optimization procedure}

A two factor experimental set up was used with age group and type of grass as the independent factors at three levels each as shown in Table 2. The data obtained was analysed by response surface methodology (RSM) based on quadratic model to optimize dependent variables. Sixteen combinations including four replicates of the center point was performed in random order according to the design. The experimental data obtained were analysed statistically using analysis of variance (ANOVA) technique at $5 \%$ level of significance.

\subsection{Physiological parameters}

The physiological parameters of agriculture workers such as heart rate, pulse rate, oxygen consumption rate and energy 
expenditure rate were recorded at the start of work and after every 10 minutes of work. All three subjects (agricultural workers) were allowed to perform chaff cutting operations on schedules for 10 minutes duration to three replications then the average values for each physiological parameter were calculated for each subject. Observation on physiological was recorded as follows:

\subsubsection{Basal metabolic rate (BMR)}

BMR is the amount of energy expended while at rest in a neutrally temperate environment and at a post-absorptive state. A popular way to estimate BMR is the Harris-Benedict formula, which takes into account all the weight, height, age, and gender (Frankenfield et al., 2013).

Women: $B M R=655+(9.6 \times$ weight in $\mathrm{kg})+(1.8 \times$ height in $\mathrm{cm})-$ (4.7×age in years) .... (1)

Men: $\mathrm{BMR}=66+(13.7 \times$ weight in $\mathrm{kg})+(5 \times$ height in $\mathrm{cm})-(6.8 \times$ age in years) ...... (2)

\subsubsection{Heart rate (beats $\mathrm{min}^{-1}$ )}

The heart rate (beats $\mathrm{min}^{-1}$ ) was recorded before and after the chaff cutting operation and was measured by using a stethoscope. Heart rate is a major parameter in the quantification of drudgery (Mohanty et al., 2008). The heart rate is a better indicator of work's overall physiological demand than energy consumption, and it has the added benefit of being much easier to calculate in the field. In order to determine cardiovascular workload, the heart rate of the subjects was assessed in the current study. The intensity of physical exercise and oxygen consumption have a linear relationship, particularly when the steady state is reached (Singh, 2013). The use of heart rate monitors is a popular means to determine the degree of physical exertion. The constant fluctuations in heart rates occur due to changes in breathing rate, blood pressure, hormones, various actions of the sympathetic and parasympathetic nervous systems and emotional states, as well as working postures, environmental influences and health status, complicating the analysis of heart rate responses due to a specific activity alone (Singh et al., 2011).

\subsubsection{Pulse rate (beats $\mathrm{min}^{-1}$ )}

Pulse rate (beats per minute) was recorded at the wrist. Place two fingers between the bone and the tendon over your radial artery which is located on the thumb side of your wrist. When you feel your pulse, count the number of beats in min.

\subsubsection{Oxygen consumption rate $\left(L \mathrm{~min}^{-1}\right)$}

The oxygen consumption rate (amount of oxygen consumed by the whole body per unit time) was dependent on the heart rate values of the operators. It was calculated by using the following mathematical formula (Kumar et al., 2013).

Oxygen consumption rate $=0.0114 \times \mathrm{HR}-0.68 \mathrm{~L} \mathrm{~min}^{-1} \ldots \ldots$. (3)

\subsubsection{Energy expenditure rate $\left(\mathrm{kJ} \mathrm{min}^{-1}\right)$}

Energy expenditure is the amount of energy that a person needs to carry out physical functions such as breathing, circulating blood, digesting food or exercising. It is measured in calories, and our total daily energy expenditure (TDEE) is the number of calories we burn each day. Nag et al., 1980, conducted a comprehensive study on Indian agricultural operators to determine occupational workload using cardiorespiratory responses and individual work ability. They divided agricultural operations into four categories: light, moderate, high, and extremely heavy, which correspond to energy costs, $\mathrm{OCR}$, and $\mathrm{VO}_{2}$ max percentages. Accordingly, operating the chaff cutter with a single operator can be put in the 'heavy' category but with two operators, it is a 'moderate' work.

$\mathrm{EER}=\mathrm{OCR} \times 20.8 \mathrm{KJ} \mathrm{\textrm {min } ^ { - 1 }}$

Where, $\mathrm{OCR}=$ Oxygen consumption rate $\left(\mathrm{L} \mathrm{min}^{-1}\right)$ and 20.88 $\mathrm{KJ} \mathrm{L}^{-1}$ is calorific value of oxygen.

\section{Results and Discussion}

The results of physiological characteristics of 3 female workers (P1, P2, and P3) at different age group participated in the experiment for ergonomic evaluation of chaff cutter was given below.

\subsection{Heart rate response for female workers (beats min $^{-1}$ )}

The heart rate of women workers recorded during the test period is presented in Table 2. The observations recorded for the heart rate of women workers are increased after operation, when compared to before operation of chaff cutter. The highest heart rate was observed as 120 beats min $^{-1}$ while cutting elephant grass followed by 117 and 110 beats $\min ^{-1}$ for jowar and pearl millet. It is due to stem thickness and hand cranking capability; the heart rate is increased for subject 3 (Adarsh et al., 2010). Obtained values of heart rate are significant $(p<0.05)$ (Figure 1$)$.

\subsection{Pulse rate (beats $\mathrm{min}^{-1}$ )}

The pulse rate of women workers recorded during the test period is presented in Table 3. The observations recorded for the pulse rate of women workers reveal that, the pulse rates increase with increasing the passage time. The highest pulse rate was observed as 87 beats $\mathrm{min}^{-1}$ under jowar followed by 84 and 78 beats min $^{-1}$ for elephant grass and pearl millet.

\begin{tabular}{lcccccc}
\hline \multicolumn{6}{c}{ Table 2: Physiological parameters of subjects } \\
\hline $\begin{array}{l}\text { Sub- } \\
\text { ject }\end{array}$ & $\begin{array}{c}\text { Age } \\
\text { group } \\
\text { (yrs.) }\end{array}$ & $\begin{array}{c}\text { Height } \\
\text { (cm) }\end{array}$ & $\begin{array}{c}\text { Weight } \\
(\mathrm{kg})\end{array}$ & $\begin{array}{c}\text { Heart } \\
\text { rate } \\
(\text { Beats } \\
\left.\mathrm{min}^{-1}\right)\end{array}$ & $\begin{array}{c}\text { Pulse } \\
\text { rate } \\
(\text { Beats } \\
\left.\mathrm{min}^{-1}\right)\end{array}$ & BMR \\
\hline P1 & $\begin{array}{l}(10-20) \\
18\end{array}$ & 148 & 42 & 79 & 62 & 1240 \\
P2 & $\begin{array}{l}(20-30) \\
21\end{array}$ & 149 & 52 & 76 & 68 & 1323.7 \\
P3 & $\begin{array}{l}\text { (30-40) } \\
35\end{array}$ & 154 & 48 & 81 & 63 & 1228.5 \\
\hline
\end{tabular}




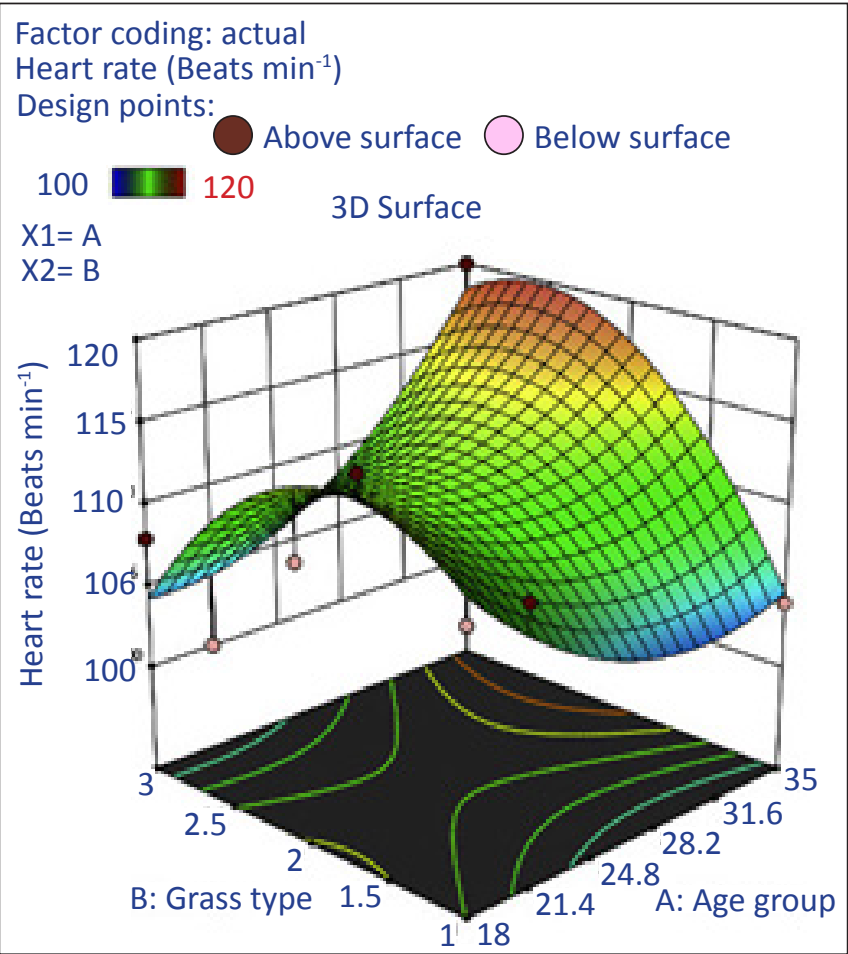

Figure 1: Heart rate of three subjects for different fodders after operation

The pulse rate increased for subject 3 due to stem thickness, hand cranking capability and workload (Figure 2).

\subsection{Oxygen consumption rate ( $L$ min-1)}

The oxygen consumption rate of women workers was

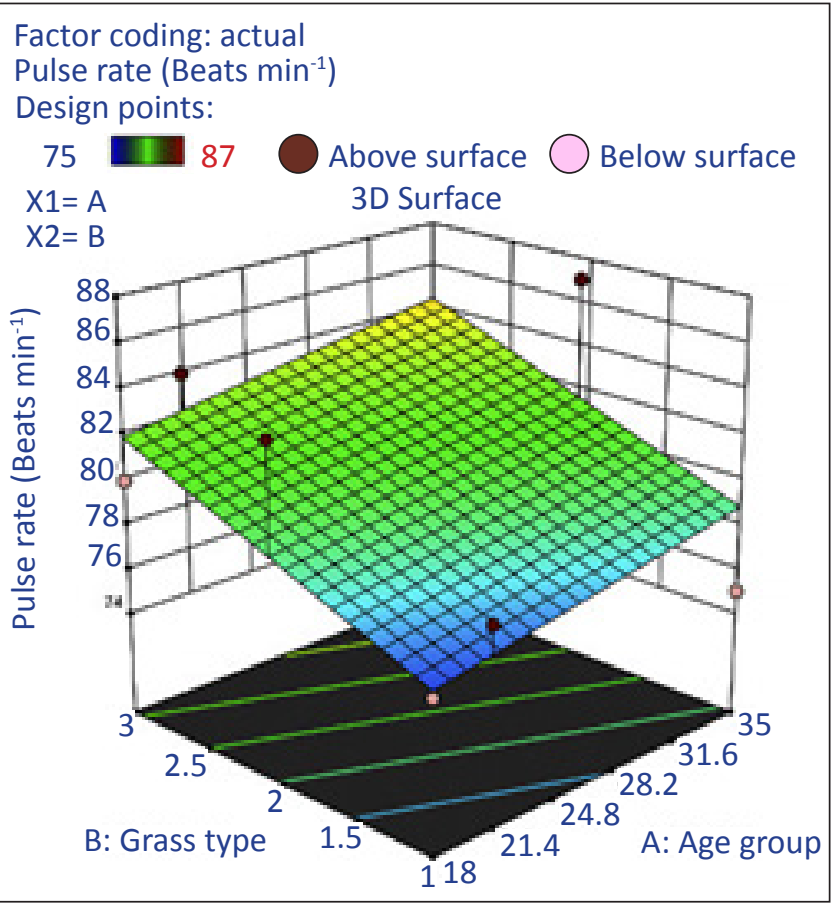

Figure 2: Pulse rate of three subjects for different fodders after operation

calculated using the heart rate, presented in Table 3. The relationship between the heart rate and oxygen consumption of the subjects was found to be linear for all subjects, which was in close agreement with results reported by Bridger (1995). The linear relationship differed from individual to individual due to difference in subject's age, weight and

\begin{tabular}{lclcccc}
\hline \multicolumn{6}{l}{ Table 3: Quadratic experimental design for optimization of physiological parameters of women workers } \\
\hline Run & Age group & Type of grass & Heart rate (beats min $^{-1}$ ) & Pulse rate (beats min m $^{-1}$ OCR (Litre min $\left.^{-1}\right)$ & EER (KJ min ${ }^{-1}$ ) \\
\hline 1 & 18 & Elephant grass & 108 & 80 & 0.594 & 12.34 \\
2 & 21 & Pearl millet & 110 & 78 & 0.618 & 12.85 \\
3 & 21 & Jowar & 114 & 78 & 0.665 & 13.83 \\
4 & 21 & Elephant grass & 100 & 84 & 0.5 & 10.4 \\
5 & 21 & Jowar & 114 & 78 & 0.665 & 13.83 \\
6 & 35 & Pearl millet & 104 & 75 & 0.547 & 11.34 \\
7 & 21 & Elephant grass & 100 & 84 & 0.5 & 10.4 \\
8 & 18 & Pearl millet & 110 & 76 & 0.618 & 12.85 \\
9 & 21 & Jowar & 114 & 78 & 0.665 & 13.83 \\
10 & 35 & Elephant grass & 120 & 83 & 0.736 & 15.3 \\
11 & 18 & Elephant grass & 108 & 80 & 0.594 & 12.34 \\
12 & 18 & Pearl millet & 110 & 76 & 0.618 & 12.85 \\
13 & 21 & Jowar & 114 & 78 & 0.665 & 13.83 \\
14 & 18 & Jowar & 110 & 84 & 0.618 & 12.85 \\
15 & 35 & Jowar & 117 & 87 & 0.7 & 14.56 \\
16 & 21 & Pearl millet & 110 & 78 & 0.618 & 12.85 \\
\hline
\end{tabular}


stature. The oxygen consumption rate of women workers increased after the operation of the chaff cutter. The highest oxygen consumption rate was observed as $0.736 \mathrm{~L} \mathrm{~min}^{-1}$ under elephant grass followed by $0.665 \mathrm{~L} \mathrm{~min}^{-1}$ for Jowar and 0.618 $\mathrm{L} \mathrm{min}^{-1}$ for Pearl millet. The highest oxygen consumption rate is observed mainly in subject 3 due to increased heart rate, pulse rate (Figure 3 ).

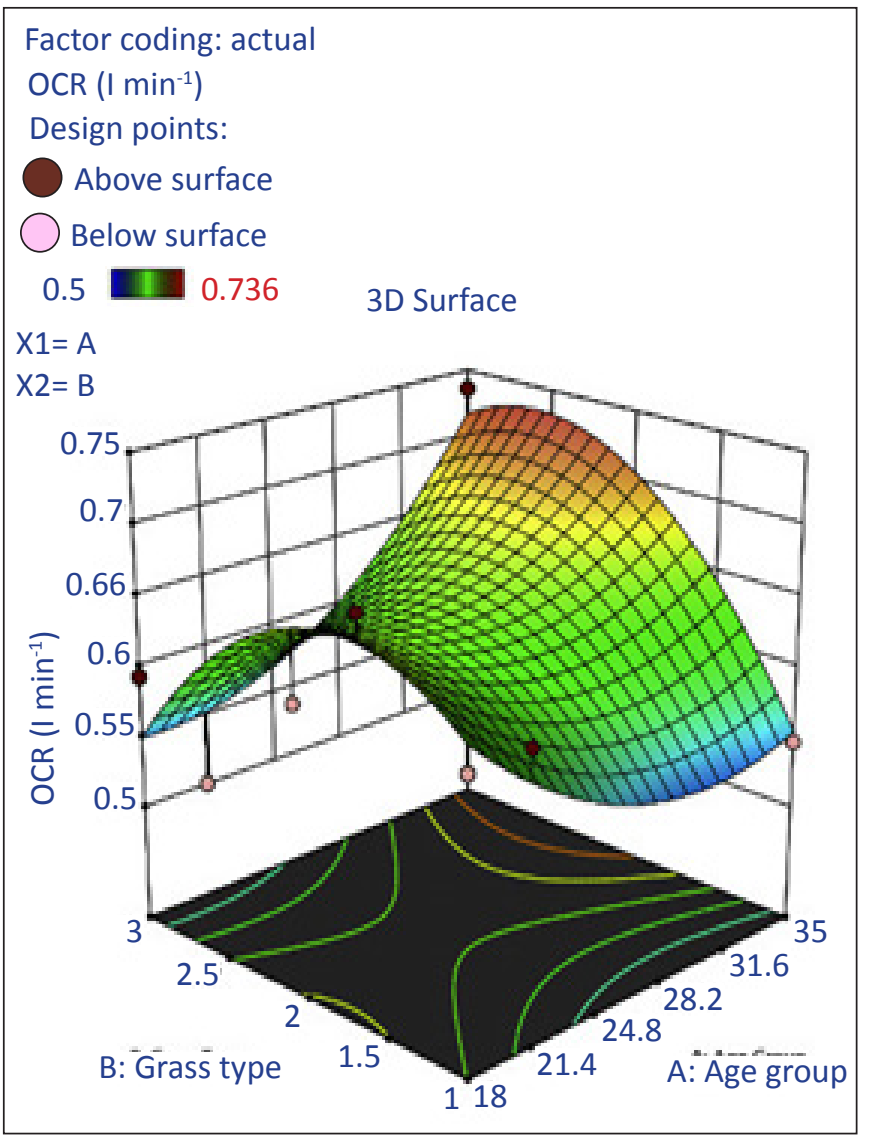

Figure 3: Oxygen consumption rate of three subjects for different fodders

\subsection{Energy expenditure rate $\left(K J \mathrm{~min}^{-1}\right)$}

The energy expenditure rate of subjects was calculated using oxygen consumption rate and calorific value of oxygen. It was increased after the operation of chaff cutter because of increase in heart and pulse rate. The highest energy expenditure rate was observed in subject 3 while cutting elephant grass. Nag et al. (1980) conducted an extensive study on Indian agricultural operators to assess the occupational workload on the basis of cardio-respiratory responses and individual capacity to perform work. They classified the work intensity of agricultural operations in terms of 'light', 'moderate', 'heavy' and 'extremely heavy' which corresponds to energy cost values, OCR and percentage of VO2 max. Accordingly chaff cutting operation can be put in to moderate work category (Figure 4).

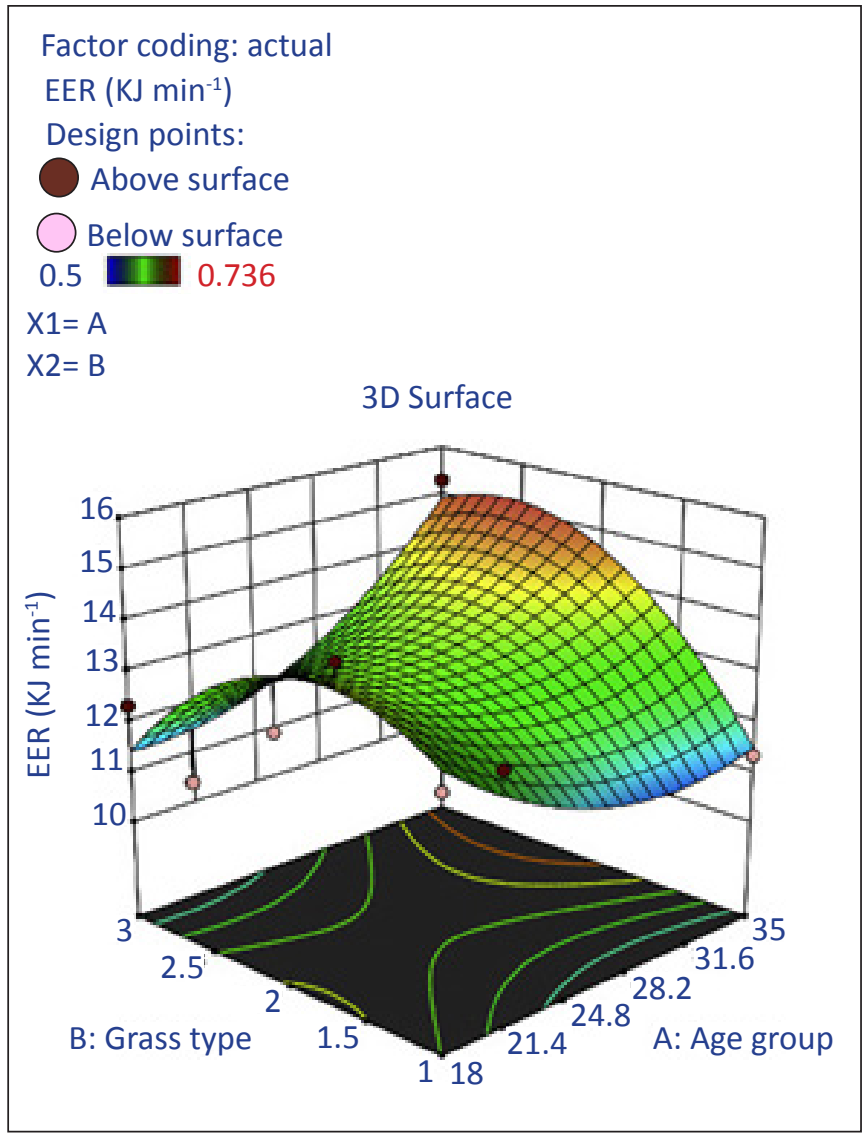

Figure 4: Energy expenditure rate of three subjects for different fodders

\section{Conclusion}

Evaluation of hand operated chaff cutter was done based on the ergonomic considerations for human comfort and safety. Physiological parameters of workers have been considered before and after operating the chaff cutter for evaluation of the machine. Based on the results of various experiments conducted under this study, the physiological parameters like heart rate, pulse rate, $\mathrm{OCR}$, and EER of female workers were varying for different age groups and rapidly increased after the operation of chaff cutter using various fodders.

\section{References}

Adarsh, K., Singh, J.K., Charanjit, S., 2010. Ergonomic assessment of a manual fodder cutter. Journal of Agricultural Engineering 47(4), 1-9.

Agrawal, K.N., Singh, R.K.P., Satapathy, K.K., 2010. Anthropometric considerations for farm tools/machinery design for tribal workers of North Eastern India. Agricultural Engineering International: The CIGRE Journal 12(1), 143-150.

Bridger, R.S., 1995. Introduction to Ergonomics, McGrawHill. New York, USA.

Bridger, R.S., Ashford, A.I., Wattie, S., Dobson, K., Fisher, I., 
Pisula, P.J., 2018. Sustained attention when squatting with and without an exoskeleton for the lower limbs. International Journal of Industrial Ergonomics 66, 230-239.

Chander, M., 2010. Chaff cutters and fodder chaffing: a simple technology worth adoption. Successes and Failures with Animal Nutrition Practices and Technologies in Developing Countries, 133.

Chayal, K., Dhaka, L., 2010. Analysis of role performance of women in farm activities, Indian Research Journal of Extension Education (10), 109-112.

Frankenfield, D.C., Ashcraft, C.M., Galvan, D.A., 2013. Prediction of resting metabolic rate in critically ill patients at the extremes of body mass index. Journal of Parenteral and Enteral Nutrition 37(3), 361-367.

Gangopadhyay, S., Dev, S., 2014. Design and evaluation of ergonomic interventions for the prevention of musculoskeletal disorders in India. Annals of occupational and environmental medicine 26(1), 1-6.

Jalali, A.R., Norgaard, P., Weisbjerg, M.R., Nielsen, M.O., 2012. Effect of forage quality on intake, chewing activity, faecal particle size distribution and digestibility of neutral detergent fibre in sheep, goats, and Ilamas. Small ruminant research 103(2-3), 143-151.

Jha, A.N.A.M.I.K.A., Tiwari, K.B., 2014. Anthropometry of female agricultural workers Jabalpur. Agriculture for Sustainable Development 2(1), 62-64.

Kathrivel, K., Sivakumar, S.S., 2003. Empowerment of women in agriculture. Coordination Committee Report of AICRP on Ergonomics and Safety in Agriculture, 30. Tamil Nadu Agricultural University, India.

Kumar, A.A., Haribabu, B., Rao, A.S., Someswararao, C., 2013. Ergonomical evaluation of manually operated weeder under wet land condition. Scientific Research and Essays 8(6), 249-255.
Mohan, D., Kumar, A., Patel, R., Varghese, M., 2004. Development of safer fodder-cutter machines: a case study from north India. Safety science 42(1), 43-55.

Mohanty, S.K., Behera, B.K., Satapathy, G.C., 2008. Ergonomics of farm women in manual paddy threshing. Journal of International Commission of Agriculture and Biosystems Engineering 10(1), 1-14.

Mohanty, S.K., Mishra, J.N., Ghosal, M.K., 2012. Ergonomical evaluation of paddy transplanting operations in Odisha. International Journal of Agricultural Engineering 5(2), 153-157.

Nag, P.K., Sebastian, N.C., Mavlankar, M.G., 1980. Occupational workload of Indian agricultural workers. Ergonomics 23(2), 91-102.

Singh, S., Sinwal, N., Rathore, H., Sinwal, S., 2011. Assessment of physiological workload related to selected manual material handling tasks. The Anthropologist 13(4), 293-298.

Singh, S.P., 2013. Ergonomical evaluation of hand operated maize dehusker-sheller with farm women. Agricultural Engineering International: CIGR Journal 15(2), 194-202.

Singh, S.P., Gite, L.P., 2007. Ergonomical evaluation of a hand operated paddy winnower by women workers. Journal of Agricultural Engineering 44(4), 67-71.

Verma, N., Singh, M.P., Nath, A., Kashyap, P., Singh, S.P., Panwar, A.S., 2020. Feminine farm operational methods, involvement, hardships and sensitivity in farming systems analysis. Indian Journal of Agricultural Sciences 90(1), 96-101.

Yadav, R., Nashik, S., Patel, N.C., Gite, L.P., 2010. Analytical study of strength parameters of Indian farm workers and its implication in equipment design. Agricultural Engineering International: CIGR Journal 12(2), 49-54. 